\title{
Glycemic control, medication adherence, and injection practices among diabetic patients treated in the 3 tertiary referral hospitals in Bhutan: a call for more action
}

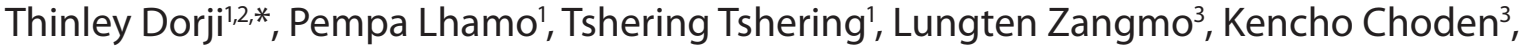 \\ Deki Choden ${ }^{4}$, Kesang Namgyal'
}

\begin{abstract}
Background: The burden of diabetes has increased rapidly with an increasing cost of treatment.

Objectives: To describe the glycemic control, injection practices, and treatment adherence among diabetic patients treated with insulin.

Methods: This cross-sectional study was conducted using a convenience sampling method at the 3 tertiary referral hospitals in Bhutan. Sociodemographic, injection practices, and clinical details were collected. Good glycemic control was defined as glycated hemoglobin $\mathrm{A}\left(\mathrm{HbA}_{1 \mathrm{c}}\right)<7 \%$ if available or fasting blood sugar $70-130 \mathrm{mg} / \mathrm{dL}$ and $2 \mathrm{~h}$ postprandial blood sugar $<180 \mathrm{mg} / \mathrm{dL}_{\text {if }} \mathrm{HbA}_{1 \mathrm{c}}$ values were unavailable. Medication adherence was assessed using the Morisky, Green and Levine (MGL) scale. The injection technique was assessed using a 10-item checklist.

Results: We studied 207 patients. Good glycemic control was achieved by only 58 (28.0\%) of patients. Using the MGL scale score, the objective adherence with insulin therapy was mostly low to medium and a gross discordance was with self-declared adherence $(P<0.001)$. The injection technique was fair to poor in half of the participants. Those with good injection techniques also had good adherence to medication $(P=0.025$, adjusted odds ratio $=4.4,95 \%$ confidence interval 1.2-16.4). The majority $(154,74.4 \%)$ had self-injected insulin, while the remaining were dependent on their home caregivers. Forty percent of the participants used storage practices that were not recommended. The disposal of the used insulin needles was generally unsafe.

Conclusions: Glycemic control and adherence to insulin administration recommendations were poor. The injection technique needs to be improved and standardized, and methods of safe disposal of sharps need to be developed.
\end{abstract}

Keywords: Bhutan, developing countries, diabetes mellitus, insulin, medication adherence

Bhutan is facing a steady increase in the burden of diabetes and noncommunicable diseases [1]. The burden of diabetes has increased rapidly from 47 per 10,000 population in 2010 to 158 per 10,000 population in $2016[1,2]$. This is against a background of $87.3 \%$ of the urban population being exposed to at least 1 risk factor for noncommunicable diseases such

*Correspondence to: Thinley Dorji, Kidu Medical Unit, His Majesty's Peoples' Project, Jigme Dorji Wangchuck National Referral Hospital, Thimphu 11001, Bhutan, e-mail: tdorji@health.gov.bt 'Jigme Dorji Wangchuck National Referral Hospital, Thimphu 11001, Bhutan ${ }^{2}$ Kidu Medical Unit, His Majesty's Peoples' Project, Thimphu 11001, Bhutan ${ }^{3}$ Central Regional Referral Hospital, Gelegphu 31101, Bhutan ${ }^{4}$ Eastern Regional Referral Hospital, Monggar 43001, Bhutan ¿ Open Access. ๑ 2018 Thinley Dorji et al., published by Sciendo. (c) Br-Nc-ND This work is licensed under the Creative Commons Attribution NonCommercial-NoDerivatives 4.0 License. 
as smoking, physical inactivity, inadequate consumption of fruits and vegetables, excess body weight, and concomitant hypertension [3].

The care for diabetes including insulin is provided free of cost in Bhutan under its universal free healthcare system [4]. The International Diabetes Federation estimated that the mean diabetes-related expenditure per person with diabetes in Bhutan for the year 2017 was USD 143 [5] where analog insulin accounted for half of the total expenditure [6]. Therefore, in Bhutan's settings, insulin is prescribed only to selected patients in whom oral glucose-lowering agents are ineffective in achieving glycemic control, or when glycemic control becomes extremely important against a background of end organ damage.

The treatment of diabetes is given according to the guidelines in the Diabetes Handbook and is monitored by the Lifestyle Related Diseases Program. A review in 2015 revealed high rates of loss to follow-up for care and shortcomings in monitoring of diabetes care and poor glycemic control [7]. Therefore, we studied factors related to glycemic control, adherence to insulin, and correctness of injection techniques among those patients with diabetes at Bhutan's 3 tertiary hospitals.

\section{Method}

\section{Study design and setting}

This study was a cross-sectional design conducted at the 3 tertiary hospitals in Bhutan: the National Referral Hospital in Thimphu district, the Central Regional Referral Hospital in Gelegphu, and Eastern Regional Referral Hospital in Monggar.

Bhutan has a 3-tiered free healthcare system with Basic Health Units and Outreach Clinics at the primary level [4]. Only selected oral glucose-lowering agents are available in these centers through the National List of Essential Medicines. At the secondary level, there are district and general hospitals where there are general doctors and insulin is available for prescription. There are 3 tertiary level hospitals where there are general physicians who provide expert management of diabetes. With only 4.3 doctors per 10,000 population, Bhutan does not have specialist endocrinologists or diabetologists. There are no strict referral systems, and patients can choose to have specialist consultations by presenting directly to the tertiary hospitals.

Fasting blood sugar (FBS) and $2 \mathrm{~h}$ postprandial blood sugar (PPBS) levels were measured using a glucose reagent kit (Dirui) containing hexokinase colorimetric assay reagents. Glycated hemoglobin A $\left(\mathrm{HbA}_{1 \mathrm{c}}\right)$ was measured using a Norudia $\left(\mathrm{HbA}_{1 \mathrm{c}}\right)$ Glycated Hemoglobin Kit (Sekisui Medical Co) containing enzymatic assay reagents including protease, fructosyl peptide oxidase, peroxidase, and 10-(carboxymethyl aminocarbonyl)-3,7-bis(dimethylamino)phenothiazine sodium salt as a chromogen. All laboratories in the country use the same method, and the laboratories in the 3 referral hospitals have passed external quality assurance.

The study was conducted between 1 January 2017 and 30 June 2017. This study received ethics approval from the Research Ethics Board of Health, Ministry of Health, Bhutan (approval No. REBH/Approval/2016/047). Study participants were recruited only after they provided documented consent on the consent form approved by the ethics board; or after they provided verbal consent that was witnessed and documented in writing if they could not read or write Dzongkha or English. Patient participants were interviewed in the nurse's duty room in the hospitals to provide privacy during the interview. Only anonymized data are presented in this paper.

\section{Study participants}

A convenience sampling technique was used for this study. Consenting consecutive patients on a stable dose of insulin for $>3$ months were recruited for the study. For the purpose of this study, "stable dose of insulin" was defined as the dose that is adjustable in an outpatient clinical setting and not requiring admission into a ward. Patients with gestational diabetes mellitus and cognitive impairment were excluded.

\section{Data collection}

Patients attending the diabetes clinics were invited to participate after providing verbal and written information about the study. Those who signed the voluntary consent form were interviewed by trained diabetes nurses using a questionnaire. Sociodemographic and injection practice details were collected using a questionnaire that was pretested $(n=20)$ at the National Referral Hospital to assess its face and content validity.

The criteria for patient clinical information, such as the type of diabetes, $\mathrm{HbA}_{1 \mathrm{c}}$, FBS, and $2 \mathrm{~h}$ PPBS, were extracted from the Diabetes Handbook. The threshold for defining good control was based on the American Diabetes Association cutoff $\mathrm{HbA}_{1 \mathrm{c}}<7 \%$ if available and FBS $70-130 \mathrm{mg} / \mathrm{dL}$ and PPBS $<180 \mathrm{mg} / \mathrm{dL}_{\text {if }} \mathrm{HbA}_{1 \mathrm{c}}$ values were unavailable $[7,8]$.

The adherence to medication was measured with the 4-item Morisky, Green and Levine (MGL) scale [9]. An MGL 
score of 0 was categorized as a high level of adherence, a score of 1-2 as a medium level of adherence, and score of 3-4 as a low level of adherence. We also measured self-reported autoadherence using the following formula:

$\frac{\text { Total number of insulin injections }}{\text { Total number of prescribed injections }} \times 100$

A 10-item checklist (Table 1) based on a guide from the American Diabetes Association was developed for the purpose of this study to assess the important steps in insulin injection [10]. Participants were asked to demonstrate their injection techniques on a sponge with an insulin syringe or $1 \mathrm{~mL}$ syringe and needle, while the nurses scored the technique against the checklist. For the purpose of this study, a score of 8-10 on the checklist was categorized as good technique, 6-7 was categorized as satisfactory, and any score $<6$ was categorized as poor.

\section{Data entry and analysis}

The data were entered into a trial version of IBM SPSS Statistics for Windows (version 23.0) by 2 investigators, and errors were corrected. The data were analyzed using Stata 13

Table 1. The 10-item checklist used to assess insulin injection technique for those among insulin-dependent diabetic patients using an insulin syringe or syringe and needle who were interviewed at the 3 tertiary hospitals in Bhutan in 2017

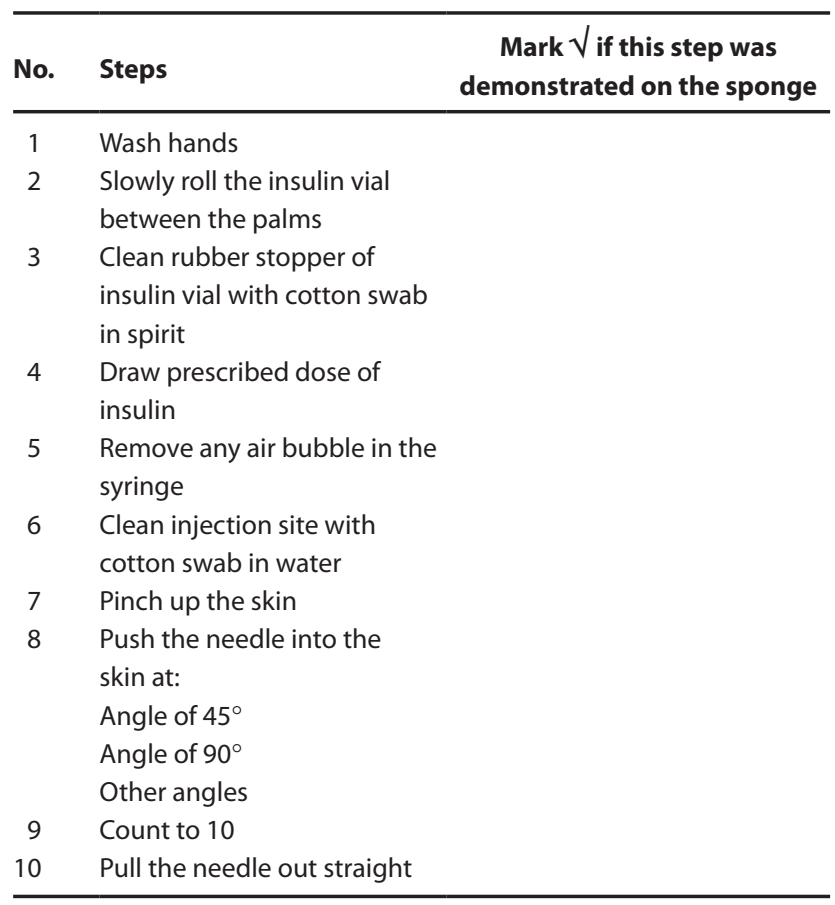

Continuous variables were assessed for normality using a Shapiro-Wilk test and are expressed as mean \pm SD; categorical data are expressed as percentage. A Kruskal-Wallis test was conducted between the objective and subjective measures of adherence. Logistic regression was conducted to identify if age, body mass index, occupation, education, type and duration of diabetes, presence of comorbidities, and insulin delivery devices influenced the glycemic control (yes/no) and injection technique (good/fair-poor). $P<0.05$ was considered as significant.

\section{Results}

In the present study, there were 207 patient participants: 101 from the National Referral Hospital, 91 from the Central Regional Referral Hospital, and 15 from the Eastern Regional Referral Hospital. The mean age was 55 years $( \pm 13.8$ years; range 20-83 years); 128 (61.8\%) were male; 195 (94.2\%) had Type 2 diabetes and 12 (5.8\%) had Type 1 diabetes. The mean duration of diabetes was 10.6 years $( \pm 7.8$ years $)$. The clinical and demographic profile of the study sample is described in Table 2.

\section{Glycemic control and adherence}

Glycemic control was achieved by only 58 (28.0\%) respondents (Table 3). Over half $(118 ; 57.0 \%)$ of the participants had their $\mathrm{HbA}_{1 \mathrm{c}}$ monitored by the hospitals, while only $33(15.9 \%)$ respondents performed self-monitoring of blood glucose. Follow-up at the diabetes clinic was undergone monthly by $140(67.6 \%)$ participants, bimonthly by 66 (31.9\%) participants, and every three months by 1 participant. The majority of participants, $201(97.1 \%)$, knew the first step in the management of hypoglycemic events.

The adherence measured using the MGL score was low to medium in $128(61.8 \%)$ participants as shown in Table 3. However, self-declared auto-adherence was high in 196 (score $\geq 95 \%$ ) participants. A Kruskal-Wallis test showed a significant difference between the objective and subjective measures of adherence $(P<0.001)$.

\section{Injection technique and current practices}

The practices related to insulin injection are shown in Table 4. Among those using a syringe or needles, the average number of reuse of syringes was 2.4 times $( \pm 1.7)$. The majority (202; 
Table 2. The clinical and demographic profile of insulin-dependent diabetic patients interviewed at the 3 tertiary hospitals in Bhutan in $2017(\mathrm{~N}=207)$

\begin{tabular}{|c|c|c|c|c|}
\hline & \multirow{2}{*}{$\begin{array}{r}\text { Type } 1 \\
\text { diabetes } \\
\mathbf{n}\end{array}$} & \multirow{2}{*}{$\begin{array}{r}\text { Type } 2 \\
\text { diabetes } \\
\mathbf{n}\end{array}$} & \multicolumn{2}{|c|}{ Total } \\
\hline & & & $\mathbf{n}$ & $\%$ \\
\hline \multicolumn{5}{|l|}{ Age (years) } \\
\hline $20-29$ & 7 & 6 & 13 & 6.3 \\
\hline $30-39$ & 2 & 12 & 14 & 6.8 \\
\hline $40-49$ & 0 & 35 & 35 & 16.9 \\
\hline $50-59$ & 0 & 59 & 59 & 28.5 \\
\hline$\geq 60$ & 0 & 86 & 86 & 41.5 \\
\hline \multicolumn{5}{|l|}{ Occupation } \\
\hline Farmer & 2 & 55 & 57 & 27.5 \\
\hline Housewife & 1 & 54 & 55 & 26.6 \\
\hline Dependent & 4 & 31 & 35 & 16.9 \\
\hline Private sector & 1 & 32 & 33 & 15.9 \\
\hline Government employee & 1 & 16 & 17 & 8.2 \\
\hline Others & 0 & 10 & 10 & 4.8 \\
\hline \multicolumn{5}{|l|}{ Level of education } \\
\hline Cannot read or write & 1 & 101 & 102 & 49.3 \\
\hline Monastic & 0 & 10 & 10 & 4.8 \\
\hline Nonformal (NFE certificate) & 1 & 6 & 7 & 3.4 \\
\hline Primary school & 0 & 33 & 33 & 15.9 \\
\hline Secondary school & 4 & 16 & 42 & 20.3 \\
\hline Undergraduate and above & 0 & 13 & 13 & 6.3 \\
\hline \multicolumn{5}{|l|}{ BMI classification $\left(\mathrm{kg} / \mathrm{m}^{2}\right)$} \\
\hline Underweight (<18.5) & 2 & 5 & 7 & 3.4 \\
\hline Normal (18.5-24.9) & 6 & 51 & 59 & 28.5 \\
\hline Overweight (25-29.9) & 1 & 79 & 82 & 39.6 \\
\hline Obese $(\geq 30)$ & 0 & 59 & 59 & 28.5 \\
\hline \multicolumn{5}{|l|}{ Comorbidities } \\
\hline Hypertension & 3 & 157 & 160 & 77.3 \\
\hline Chronic kidney disease & 1 & 48 & 49 & 23.7 \\
\hline Dyslipidemia & 2 & 75 & 77 & 37.2 \\
\hline
\end{tabular}

BMI, body mass index; NFE, Nonformal Education
Table 3. Measurement of glycemic control, adherence, and the injection technique score among insulin-dependent diabetic patients interviewed at the 3 tertiary hospitals in Bhutan in 2017

\begin{tabular}{|c|c|c|c|c|}
\hline & \multirow{2}{*}{$\begin{array}{r}\text { Type } 1 \\
\text { diabetes }\end{array}$} & \multirow{2}{*}{$\begin{array}{r}\text { Type } 2 \\
\text { diabetes }\end{array}$} & \multicolumn{2}{|c|}{ Total } \\
\hline & & & $\mathbf{n}$ & $\%$ \\
\hline \multicolumn{5}{|l|}{$\mathrm{HbA}_{1 \mathrm{c}}$ level $(\mathrm{n}=118)$} \\
\hline$<7 \%$ & 1 & 45 & 46 & 39.0 \\
\hline$\geq 7 \%$ & 6 & 66 & 72 & 61.0 \\
\hline \multicolumn{5}{|c|}{ Fasting blood sugar $(n=203)$} \\
\hline$\leq 130 \mathrm{mg} / \mathrm{dL}$ & 2 & 79 & 81 & 39.9 \\
\hline$>130 \mathrm{mg} / \mathrm{dL}$ & 5 & 117 & 122 & 60.1 \\
\hline \multicolumn{5}{|c|}{$\begin{array}{l}\text { Two-hour postprandial blood } \\
\text { sugar }(n=203)\end{array}$} \\
\hline$\leq 180 \mathrm{mg} / \mathrm{dL}$ & 2 & 67 & 69 & 33.9 \\
\hline$>180 \mathrm{mg} / \mathrm{dL}$ & 6 & 128 & 134 & 66.1 \\
\hline \multicolumn{5}{|c|}{ Objective measure of adherence } \\
\hline \multicolumn{5}{|c|}{ with medication (MGL score, $n=207$ ) } \\
\hline High (score 0) & 4 & 75 & 79 & 38.2 \\
\hline Medium (score 1-2) & 4 & 97 & 101 & 48.8 \\
\hline Low (score (3-4) & 1 & 26 & 27 & 13.0 \\
\hline \multicolumn{5}{|l|}{ Injection technique } \\
\hline \multicolumn{5}{|l|}{ score $(n=205)$} \\
\hline Good (score 8-10) & 4 & 96 & 100 & 49.5 \\
\hline Fair (score 6-7) & 4 & 55 & 59 & 29.2 \\
\hline Poor (score 0-5) & 0 & 43 & 43 & 21.3 \\
\hline
\end{tabular}

HbA1c, glycated hemoglobin A; MGL, Morisky, Green and Levine

Unsafe disposal practices were highly prevalent as shown in Table 4. However, knowledge of the biohazard nature of used insulin needles $(191,92.3 \%)$ and needle stick injuries $(182,87.9 \%)$ was good in the majority of participants.

\section{Discussion}

97.6\%) were prescribed soluble plus isophane (30/70) insulin. The average daily dose of insulin was 51.4 units $( \pm 26.5)$ with a range of 8-150 units. The commonly preferred sites for insulin injection were abdomen, 143 (69.1\%), followed by thigh, 136 $(65.7 \%)$, and deltoid, $61(29.5 \%)$. The injection site was rotated by $193(93.2 \%)$ participants.

The correct practice for storage of insulin (in the door of the refrigerator) was reported by only $126(60.9 \%)$ patient participants (Table 4). Just less than half of the syringe using participants $(100,49.5 \%)$ demonstrated good technique in administering insulin (Table 3 ). Those with good injection technique also had good adherence to medication $(P=0.025$, adjusted odds ratio $=4.4,95 \%$ confidence interval 1.2-16.4).
This study was an assessment of glycemic control, insulin injection techniques, and adherence to medication among those on self-medication in a real-world situation in a lowand middle-income country. Glycemic control among insulindependent diabetic patients was less than that of $37.6 \%$ among all patients with diabetes reviewed in 2015 and that of around $50 \%$ found in developed countries $[7,11,12]$. This consistent level of poor control is alarming given the background of increasing load of diabetic patients in all hospitals across Bhutan $[1,2]$. Poor glycemic control, linked to increased cost of care for diabetes and its complications [13], is a cause of concern for the free healthcare system of Bhutan. This calls for efforts in the prevention of diabetes and prevention of complications in those diagnosed with diabetes. 
Table 4. Insulin self-administration practices among insulindependent diabetic patients interviewed at the 3 tertiary hospitals in Bhutan, 2017

\begin{tabular}{|c|c|c|c|c|}
\hline & \multirow{2}{*}{$\begin{array}{r}\text { Type } 1 \\
\text { diabetes }\end{array}$} & \multirow{2}{*}{$\begin{array}{r}\text { Type } 2 \\
\text { diabetes }\end{array}$} & \multicolumn{2}{|c|}{ Total } \\
\hline & & & $\mathbf{n}$ & $\%$ \\
\hline \multicolumn{5}{|l|}{ Insulin delivery devices } \\
\hline Insulin syringe & 7 & 107 & 114 & 55.1 \\
\hline $\begin{array}{l}\text { "1 } \mathrm{mL} \text { syringe and } \\
\text { needle" }\end{array}$ & 1 & 87 & 88 & 42.5 \\
\hline Insulin pen & 1 & 4 & 5 & 2.4 \\
\hline \multicolumn{5}{|l|}{ Injection of insulin } \\
\hline Self & 7 & 147 & 154 & 74.4 \\
\hline Caregivers & 2 & 51 & 53 & 25.6 \\
\hline \multicolumn{5}{|c|}{ Number of injections per day } \\
\hline 1 & 0 & 6 & 6 & 2.9 \\
\hline 2 & 9 & 189 & 198 & 95.7 \\
\hline 3 & 0 & 3 & 3 & 1.4 \\
\hline \multicolumn{5}{|l|}{ Storage of insulin $(n=207)$} \\
\hline Door of refrigerator & 6 & 120 & 126 & 60.9 \\
\hline Freezer refrigerator & 1 & 63 & 64 & 30.9 \\
\hline Shelf of refrigerator & 2 & 8 & 10 & 4.8 \\
\hline Earthen pots & 0 & 6 & 6 & 2.9 \\
\hline $\begin{array}{l}\text { Open environment/not } \\
\text { refrigerated }\end{array}$ & 0 & 1 & 1 & 0.5 \\
\hline \multicolumn{5}{|c|}{ Injection site complications } \\
\hline Bruising & 0 & 38 & 38 & 18.4 \\
\hline Scarring & 1 & 32 & 33 & 15.9 \\
\hline Lipoatrophy & 1 & 17 & 18 & 8.7 \\
\hline Lipohypertrophy & 2 & 7 & 9 & 4.3 \\
\hline Inflammation & 0 & 2 & 2 & 1.0 \\
\hline None & 5 & 102 & 107 & 51.7 \\
\hline \multicolumn{5}{|l|}{ Disposal of sharps } \\
\hline $\begin{array}{l}\text { Dispose directly in dry } \\
\text { waste into municipal } \\
\text { waste system }\end{array}$ & 2 & 59 & 61 & 29.5 \\
\hline $\begin{array}{l}\text { Give to hospital in } \\
\text { sharps box }\end{array}$ & 2 & 42 & 44 & 21.3 \\
\hline $\begin{array}{l}\text { Give to hospital in } \\
\text { plastic bag }\end{array}$ & 1 & 22 & 23 & 11.1 \\
\hline Bury & 0 & 32 & 32 & 15.5 \\
\hline Burn & 1 & 20 & 21 & 10.1 \\
\hline $\begin{array}{l}\text { Dispose in sealed con- } \\
\text { tainer into municipal } \\
\text { waste system }\end{array}$ & 1 & 12 & 13 & 6.3 \\
\hline Store at home & 2 & 11 & 13 & 6.3 \\
\hline
\end{tabular}

Adherence with medication was not satisfactory in the majority even though patients were educated by diabetes nurses from time to time.

The education and training of diabetes health educators need to be standardized, and monitoring for adherence among patients needs to be emphasized. It is recognized that improving medication adherence has a far greater impact on the health of the population than any improvement in specific medical treatment [14]. The diabetes educators also need to empower, motivate, and educate patients at early stages of their medication to produce substantial adherence behavior $[15,16]$. As a quarter of our patients are given insulin by their caregivers, they are also recognized as an important partner in monitoring adherence to medication with good insulin administration technique and in safe disposal of used needles [17].

The other important factor of achieving glycemic control is injection technique. However, self-injection was viewed as a therapy that requires additional skill by our patients. The needle length was a significant factor for causing pain and thus acceptability $[18,19]$. It is noted that there are interruptions to the continuous supply of the standard insulin syringe in which a "1 mL syringe" that comes with a bigger gauge needle is given as a substitute. These bigger gauge needles that cause more pain during injection are a recognized barrier.

Insulin therapy generates used needles that are a biohazard waste that poses an important potential risk for needle stick injury [19]. The Drug Regulatory Authority of Bhutan has guidelines for disposal of medically related waste, but Bhutan lacks a recognized guideline or method for collecting used sharps from insulin users. As the number of insulin users and the number of those detected with human immunodeficiency or hepatitis B virus infection, or both, increase in Bhutan, the problem of inappropriate disposal of sharps poses an important threat nationwide [1].

While more than half of the Bhutanese households (56.8\%) own refrigerators [20], we found that insulin vials were sometimes stored inside the freezer compartment, which can potentially reduce the efficacy of the insulin [10]. While Bhutan has a subtropical climate in its southern belt, the temperature drops to subzero during winter months in the temperate climate of the northern parts. Therefore, greater awareness of the correct method for storage of insulin vials is needed among patients, their caregivers, and healthcare providers.

The assessment of medication adherence was conducted by health workers, which might have allowed some social desirability bias. Our present study assessed glycemic control in relation to medication adherence alone and did not ask about the level of dietary and lifestyle modifications. A future study to assess the outcomes after interventions in monitoring of glycemic control or correction of injection techniques and comparison with diabetic patients not on insulin is warranted. We also suggest performing a costeffectiveness analysis of providing an insulin pen and an evaluation of diabetic emergency events and diabetic micro/ macrovascular complications to develop locally informed diabetes treatment guidelines. 
Although convenience sampling was used for the purpose of this study, in Bhutan, physicians, dieticians, and facilities for monitoring of $\mathrm{HbA}_{1 \mathrm{c}}$ are available only at the 3 tertiary hospitals and represent the majority of the diabetic patients receiving insulin. The relative unavailability of laboratory reagents to conduct the tests is an explanation for the low prevalence of laboratory monitoring of $\mathrm{HbA}_{1 \mathrm{c}}$ in the present study sample. Monitoring FBS and PPBS levels was available to more patients. These factors may limit the glycemic control data.

The home and community environment of each insulindependent diabetic patient should be assessed, including home and community practices for disposing of solid waste, availability of clean water, and hygiene practices in the household. There is also a need to develop a system to monitor and ensure adherence to medication (injection techniques, insulin storage, supply of insulin syringes) and develop safe disposal methods for sharps used by diabetic patients.

\section{Conclusion}

Glycemic control and adherence to recommendations for insulin administration were poor among diabetic participants treated in the 3 regional tertiary referral hospitals in Bhutan. Many participants used poor injection techniques and did not dispose of sharps safely. Our present findings suggest ways in which care of patients with diabetes can be improved to increase adherence with self-care recommendations and to ensure glycemic control among insulin-dependent participants.

Author contributions. All authors jointly conceived the study and contributed in data acquisition and data entry. Data were analyzed by TD, PL, TT, and KN. All authors contributed significantly to drafting the manuscript, and TD, PL, and TT critically revised it. All authors have read and approved the final version submitted and take responsibility for statements made in the published article.

Acknowledgments. The study team thanks the Bhutan Foundation and the Medical Education Center for Research, Innovation and Training ((16)MECIRT/Research/2017/58), Khesar Gyalpo University of Medical Sciences of Bhutan, Thimphu, for the financial support and the staff of the Lifestyle Related Disease Clinics in the 3 tertiary referral hospitals for collection of data. The authors are also thankful to Sithar Dorjee, Mary Alice Lee, Nidup Dorji, Kuenzang Chhezom, Sonam Chhoden, and Indra Sharma for their review and suggestions in writing this article and Kinley Wangchuk and
Tshewang Lhaden for their help in providing information on the laboratory methods used in glycemic measurements.

Conflict of interest statement. The authors have each completed and submitted the International Committee of Medical Journal Editors Uniform Disclosure Form for Potential Conflicts of Interest. None of the authors has anything to disclose.

\section{References}

[1] Ministry of Health. Annual health bulletin 2018. Thimphu, Bhutan: Ministry of Health, Royal Government of Bhutan; 2018.

[2] Dorji T, Yangchen P, Dorji C, Nidup T, Zam K. An approach to diabetes prevention and management: the Bhutan experience. WHO South East Asia J Public Health. 2016; 5:44-7.

[3] Ministry of Health. National survey for noncommunicable disease risk factors and mental health using WHO STEPS approach in Bhutan, 2014. New Delhi: World Health Organization, Regional Office for South-East Asia; 2015

[4] Thinley S, Tshering P, Wangmo K, Wangchuk N, Dorji T, Tobgay T, Sharma J. The Kingdom of Bhutan health system review. In: Patcharanarumol W, Tangcharoensathien V, editors. Asia Pacific observatory on health systems and policies. New Delhi: World Health Organization, Regional Office for South-East Asia; c2017, 226 p (Health systems in transition, vol. 7, no. 2)

[5] International Diabetes Federation. IDF diabetes atlas. 8th ed. Brussels: International Diabetes Federation; 2017.

[6] World Health Organization. Global report on diabetes. Geneva: World Health Organization; 2016.

[7] Zam K, Kumar AM, Achanta S, Bhat P, Naik B, Zangpo K, et al. A first country-wide review of diabetes mellitus care in Bhutan: time to do better. BMC Health Serv Res. 2015; 15:389. doi: 10.1186/s12913 015-1026-6

[8] American Diabetes Association. Glycemic targets. Sec. 6. In: Standards of medical care in diabetes-2017. Diabetes Care. 2017; 40(Suppl 1):S48-56.

[9] Morisky DE, Green LW, Levine DM. Concurrent and predictive validity of a self-reported measure of medication adherence. Med Care. 1986; 24:67-74.

[10] American Diabetes Association. Insulin administration. Diabetes Care. 2004; 27(Suppl 1):S106-9.

[11] Shaya FT, Yan X, Lin PJ, Simoni-Wastila L, Bron M, Baran R, Donner TW. US trends in glycemic control, treatment, and comorbidity burden in patients with diabetes. J Clin Hypertens. $2010 ; 12: 826-32$.

[12] Lozovey NR, Lamback EB, Mota RB, Caarls MB, Neto LV. Glycemic control rate in type 2 diabetes mellitus patients at a public referral hospital in Rio de Janeiro, Brazil: demographic and clinical factors. J Endocrinol Metab. 2017; 7:61-7.

[13] Zhuo X, Zhang P, Kahn HS, Bardenheier BH, Li R, Gregg EW. Change in medical spending attributable to diabetes: national data from 1987 to 2011. Diabetes Care. 2015; 38:581-7.

[14] World Health Organization. Adherence to long-term therapies: evidence for action. Geneva: World Health Organization; 2003.

[15] Lam WY, Fresco P. Medication adherence measures: an overview. Biomed Res Int. 2015; 2015:217047. doi: 10.1155/2015/217047 
[16] Shrivastava SR, Shrivastava PS, Ramasamy J. Role of self-care in management of diabetes mellitus. J Diabetes Metab Disord. 2013; 12:14. doi: 10.1186/2251-6581-12-14

[17] Cramer JA. A systematic review of adherence with medications for diabetes. Diabetes Care. 2004; 27:1218-24.

[18] Grassi G, Scuntero P, Trepiccioni R, Marubbi F, Strauss K. Optimizing insulin injection technique and its effect on blood glucose control. J Clin Transl Endocrinol. 2014; 1:145-50.

[19] Frid AH, Kreugel G, Grassi G, Halimi S, Hicks D, Hirsch LJ, et al. New insulin delivery recommendations. Mayo Clin Proc. 2016; 91:1231-55.

[20] National Statistics Bureau. Bhutan living standards survey report 2017. Thimphu, Bhutan: National Statistics Bureau, Royal Government of Bhutan; 2017. 